Short Note

\title{
4-Chloro-2,3,5-trifluorobenzoic Acid
}

\section{Shuitao Yu ${ }^{1,2}$, Xiaohu Feng 1,2, Weiyou Zhou ${ }^{1,3}$, Zhengjun Xia ${ }^{1,2}$, Mingguang Zhang ${ }^{1,2}$, Yang Chen ${ }^{1,2}$ and Zaixin Chen ${ }^{1,2, *}$}

1 Yabang Medical Research Institute, Changzhou 213145, China;

E-Mails: pharmsyyk71@163.com (S.Y.); xiaohufeng@126.com (X.F.); zhouwy426@cczu.edu.cn (W.Z.); zhengjun_xia@163.com (Z.X.); zmg1997@aliyun.com (M.Z.); 15206111910@163.com (Y.C.)

2 Jiangsu Novel Quinolone Antibacterial Drugs Engineering Research Center, Changzhou 213145, China

3 Jiangsu Key Laboratory of Advanced Catalytic Materials and Technology, Changzhou University, Changzhou 213164, China

* Author to whom correspondence should be addressed; E-Mail: zaixin_chen@163.com; Tel.: +86-519-8806-8868.

Academic Editor: Norbert Haider

Received: 27 May 2015 / Accepted: 29 October 2015 / Published: 3 November 2015

\begin{abstract}
A new tetrahalogenated benzoic acid 4-chloro-2,3,5-trifluorobenzoic acid was synthesized from methyl 2,3,4,5-tetrafluorobenzoate via three steps. The structure of the newly synthesized compound was established by FTIR, NMR, MS and elemental analysis.
\end{abstract}

Keywords: 4-chloro-2,3,5-trifluorobenzoic acid; synthesis; amination; Sandmeyer reaction

\section{Introduction}

2,3,4,5-Tetrahalogenated benzoic acid derivatives are valuable intermediates for the synthesis of medicaments. Some of these compounds are intermediates for antibacterials such as quinolone carboxylic acids $[1,2]$. In the course of our research on biologically active compounds, we needed to prepare a synthetic precursor 1, i.e., 4-chloro-2,3,5-trifluorobenzoic acid. Although fluoroarenes are versatile components of many synthetic biologically active compounds and functional materials, up to now there has been no report of the synthesis of compound $\mathbf{1}$. 
For the synthesis of compound 1, 4-chloro-2,3,5-trifluoro aniline can be chosen as the starting material, followed by diazotization, Grignard reaction and carbonylation, but the yield of Grignard reagent should be low, and the product is difficult to purify for the interference of chloro substituents.

On the above analysis, methyltetrafluorobenzoate (2) was chosen as the reactant, and we need to convert the fluoro at 4-site to chloro. For the strong bond dissociation energies of C-F bonds, C-F activation is one of the most challenging issues in organic chemistry. However, firstly converting the fluoro to amine provides a convenient method, and then the amine could transform to chloro by diazotization (Scheme 1).<smiles>COC(=O)c1cc(F)c(F)c(F)c1F</smiles>

Scheme 1. Synthesis of 4-chloro-2,3,5-trifluorobenzoic acid.

\section{Result and Discussion}

The first step is to transform fluoro to amine, and there are two choices. The first method is converting the fluoro to azido substituent followed by reduction into amino compound, but sodium azide used in the reaction is not safe [3]; the other method is substituting the fluoro with tert-butylamine and then transforming to amine in the presence of $\mathrm{HCl}$ (Scheme 1). A moderate yield (80.8\%.) was obtained for compound 3 using the method without ortho substituted product, which might be ascribed to the steric effect of ester group. The second step is to convert amine to chloro, which could be finished by the conventional Sandmeyer procedure [4,5] involving initial diazotization of the arylamine followed by addition of the diazonium salt to the cuprous halide in an aqueous solution with the corresponding halogen acid. The satisfactory yields of aryl halides are usually obtained. In the reaction, the target molecule was obtained with a total yield of $44.1 \%$.

\section{Experimental}

\subsection{General}

The methyl tetrafluorobenzoate, tert-butylamine, sodium nitrite, and cuprous chloride were obtained from Sigma-Aldrich (Shanghai, China) and were used without further purification. Melting points were determined using OptiMelt capillary mp apparatus (Sunnyvale, CA, USA) and were uncorrected. NMR spectra were recorded on Bruker Avance $500 \mathrm{MHz}$ instrument (New York, NY, USA) using deuterated DMSO- $d_{6}$ as solvent and tetramethylsilane as internal standard. The IR spectra were recorded on NICOLET Impact 410 instrument (Madison, WI, USA) using KBr pellets. The element analysis was made on a PerkinElmer EA2400 II instrument (Waltham, MA, USA). TLC was carried out using Aladdin pre-coated plates (GF254, $250 \mu \mathrm{m}$ ) (Shanghai, China). 


\subsection{Synthesis of 4-Chloro-2,3,5-trifluorobenzoic Acid (1)}

A mixture of methyl tetrafluorobenzoate, 2, $(4.3 \mathrm{~g}, 17.4 \mathrm{mmol})$ and tert-butylamine $(7.1 \mathrm{~g}$, $97.3 \mathrm{mmol})$ in dry acetonitrile $(50 \mathrm{~mL})$ was vigorously stirred at $40{ }^{\circ} \mathrm{C}$ for $23 \mathrm{~h}$. The reaction progress was monitored by TLC (10\% ethyl acetate in hexane). The solvent was removed in vacuum. The residue was mixed with water $(15 \mathrm{~mL})$ and transferred to a separatory funnel. The mixture was extracted by dichloromethane $(3 \times 10 \mathrm{~mL})$, and the organic layer was washed with water $(2 \times 10 \mathrm{~mL})$, brine $(1 \times 10 \mathrm{~mL})$ and dried over sodium sulfate. Removal of solvent and drying in vacuum gave $4.0 \mathrm{~g}$ of orange oily product. Then, a mixture of the orange compound $(4.0 \mathrm{~g})$ and concentrated hydrochloric acid $(37 \%, 32.0 \mathrm{~g})$ was refluxed for $24 \mathrm{~h}$. The reaction progress was monitored by TLC (10\% ethyl acetate in hexane). The reaction mixture was cooled to room temperature and extracted by ethyl acetate $(2 \times 15 \mathrm{~mL})$, and the organic layer was washed with water $(2 \times 10 \mathrm{~mL})$, brine $(1 \times 10 \mathrm{~mL})$ and dried over sodium sulfate. Removal of solvent and drying in vacuum gave $2.5 \mathrm{~g}$ of white powder (3). This mixture was directly used in the next step without further purification. A mixture of the compound $\mathbf{3}$, dichloromethane $(28 \mathrm{~mL})$, water $(10 \mathrm{~mL})$, concentrated hydrochloric acid $(37 \%, 9.4 \mathrm{~g})$ and cuprous chloride (4.2 g, $42.4 \mathrm{mmol})$ was stirred for $1 \mathrm{~h}$ in an ice-salt bath. Sodium nitrite $(1.0 \mathrm{~g}, 14.5 \mathrm{mmol})$ dissolved in water $(8 \mathrm{~mL})$ was dropped into the flask slowly below $5{ }^{\circ} \mathrm{C}$. After that, the mixture was stirred under room temperature for another $4 \mathrm{~h}$. The reaction progress was monitored by TLC (10\% ethyl acetate in hexane). The reaction mixture was cooled to room temperature and extracted by dichloromethane $(2 \times 10 \mathrm{~mL})$, and the organic layer was washed with $\mathrm{Na}_{2} \mathrm{~S}_{2} \mathrm{O}_{4}$ solution $(10 \%$, $2 \times 10 \mathrm{~mL}), \mathrm{HCl}$ solution $(5 \%, 2 \times 10 \mathrm{~mL})$, decolorizated with activated carbon and dried over sodium sulfate. Removal of solvent and drying in vacuum resulted in $1.5 \mathrm{~g}$ of off-white powder, which was subjected to column chromatography $\left(\mathrm{SiO}_{2}\right)$ using gradient elution $(10 \%$ ethyl acetate in hexane, and then elution with $30 \%$ ethyl acetate in hexane). The title compound was obtained as a white crystalline solid (1.2 g).

Yield: $44.1 \%$; m.p.: $82 \sim 83{ }^{\circ} \mathrm{C}$.

$\mathrm{R}_{\mathrm{f}}(30 \%$ ethyl acetate in hexane $)=0.26$.

IR $\left(v, \mathrm{~cm}^{-1}\right): 3101(\mathrm{O}-\mathrm{H}), 1686(\mathrm{C}=\mathrm{O}), 1353(\mathrm{C}-\mathrm{F}), 905(\mathrm{C}-\mathrm{H})$.

${ }^{1} \mathrm{H}-\mathrm{NMR}\left(500 \mathrm{MHz}, \mathrm{DMSO}-d_{6}\right): \delta=7.75 \sim 7.79(\mathrm{~m}, 1 \mathrm{H}), 13.84$ (br s, $\left.1 \mathrm{H}\right), 7.73 \sim 7.78(\mathrm{~m}, 1 \mathrm{H}$, $\mathrm{D}_{2} \mathrm{O}$ exchangeable).

${ }^{19}$ F-NMR (564 MHz, DMSO- $\left.d 6\right): \delta=-136.5\left(\mathrm{~d}, J_{H-F}=5.6 \mathrm{~Hz}, 1 \mathrm{~F}\right),-149.8\left(\mathrm{~d}, J_{H-F}=22.6 \mathrm{~Hz}, 1 \mathrm{~F}\right)$, $-155.0\left(\mathrm{~d}, J_{H-F}=22.6 \mathrm{~Hz}, 1 \mathrm{~F}\right)$.

${ }^{13} \mathrm{C}-\mathrm{NMR}\left(75 \mathrm{MHz}, \mathrm{DMSO}-d_{6}\right): \delta=162.5(\mathrm{~s}), 145.3 \sim 148.8\left(\mathrm{q}, J_{C-F}=255.8 \mathrm{~Hz}\right), 143.8 \sim 147.5$ $\left(\mathrm{q}, J_{C-F}=269.6 \mathrm{~Hz}\right), 144.1 \sim 144.3\left(\mathrm{q}, J_{C-F}=12.8 \mathrm{~Hz}\right), 138.7 \sim 142.4(\mathrm{~m}), 140.4 \sim 141.9(\mathrm{~m}), 113.1 \sim 113.4$ (q, $\left.J_{C-F}=20.6 \mathrm{~Hz}\right)$.

ESI-MS: $m / z=208.9623(100)[\mathrm{M}-\mathrm{H}]^{-}, 210.9602(32)$. 
Calcd. for $\mathrm{C}_{7} \mathrm{H}_{2} \mathrm{ClF}_{3} \mathrm{O}_{2}, \mathrm{C}, 39.93 ; \mathrm{H}, 0.96$; Found: C, 39.93; H, 0.92.

${ }^{1} \mathrm{H}-,{ }^{13} \mathrm{C}$ - and ${ }^{19} \mathrm{~F}-\mathrm{NMR}$ spectra are reported in the supplementary materials as Figures $\mathrm{S} 1 \sim \mathrm{S} 2, \mathrm{~S} 3$ and S4. FTIR spectrum is reported as Figure 5 together with ESI-MS spectrum as Figure S6.

\section{Acknowledgments}

Authors are thankful to China Pharmaceutical University for providing the spectra data.

\section{Author Contributions}

Shuitao Yu, Yang Chen: Literature search and experimental synthetic work; Xiaohu Feng, Zhengjun Xia, Mingguang Zhang, Weiyou Zhou: HPLC, IR and NMR and MS interpretation, writing of manuscript; Zaixin Chen: Design of synthesis.

\section{Conflicts of Interest}

The authors declare no conflict of interest.

\section{References}

1. Sato, M.; Kawakami, H.; Motomura, T.; Aramaki, H.; Matsuda, T.; Yamashita, M.; Ito, Y.; Matsuzaki, Y.; Yamataka, K.; Ikeda, S.; et al. Quinolone carboxylic acids as a novel monoketo acid class of human immunodeficiency virus type 1 integrase inhibitors. J. Med. Chem. 2009, 52, 4869-4882.

2. Ashfaq, M.; Shah, S.S.A.; Najam, T.; Ahmad, M.M.; Tabassum, R.; Rivera, G. Synthetic Thioamide, Benzimidazole, Quinolone and Derivatives with Carboxylic Acid and Ester Moieties: A Strategy in the Design of Antituberculosis Agents. Curr. Med. Chem. 2014, 21, 911-931.

3. Lesher, G.Y. Tricyclic-Pyridinylquinoline Compounds, Their Preparation and Use. U.S. Patent 4839355 A, 13 June 1989.

4. Hodgson, H.H. The sandmeyer reaction. Chem. Rev.1947, 40, 251-277.

5. Berrouard, P.; Dufresne, S.; Pron, A.; Veilleux, J.; Leclerc, M. Low-cost synthesis and physical characterization of thieno[3,4-c]pyrrole-4,6-dione-based polymers. J. Org. Chem. 2012, 77, 8167-8173.

(C) 2015 by the authors; licensee MDPI, Basel, Switzerland. This article is an open access article distributed under the terms and conditions of the Creative Commons Attribution license (http://creativecommons.org/licenses/by/4.0/). 